\title{
Starting from scratch: building a new curriculum for faculty development program in emergency medicine by repurposing from a systemic review
}

\section{Corresponding author:}

Selma Alqattan, Kuwait Ministry of Health, 93500 Kuwait City, Kuwait, e-mail: s_alqattan@yahoo.ie
Medical Research Journal 2021; Volume 6, Number 2, 147-152 DOI: 10.5603/MRJ.a2021.0016 Copyright (C) 2021 Via Medica ISSN 2451-2591 e-ISSN 2451-4101

\begin{abstract}
Introduction: As we move towards globalization, health care professionals may find themselves working in a healthcare system that has a different patient population and disease epidemiology than their training. This study aims to develop a curriculum for a faculty development program for emergency medicine health care professionals in a private hospital in Kuwait who find themselves in such a situation.

Material and methods: Using the Preferred Reporting Items for Systematic Reviews and Meta-Analysis guidelines, the authors systematically searched PubMed, CINAHL and ERIC from the inception of the database until June 2018, for search terms that would capture curriculum development for faculty development programs in emergency medicine or trauma. Two independent reviewers for relevance reviewed abstracts; included studies were retrieved for full-text analysis. A curriculum was developed using the topics requested by the needs assessment using the recommendations from the systematic review.

Results: A total of 92 papers meeting the search criteria were identified of which 5 were included in the analysis. All 5 articles had education as the main objective of the curriculum for the faculty development program. All 5 articles had a faculty development program that was in the classroom setting. Four articles (80\%) included a target audience of senior staff. Four articles (80\%) recommended mentoring as an effective method for faculty development.

Conclusions: The most effective method of the faculty development program was through mentorship. Further research is needed to dictate faculty development focusing on non-educational objectives. Key words: faculty training
\end{abstract}

Med Res J 2021; 6 (2): 147-152

\section{Introduction}

As we move towards globalization, physicians may find themselves training in one type of healthcare system to attain formal certificates and degrees, only to find themselves practising in a different system. Health care professionals may find themselves working in a healthcare system that has a different patient population and disease epidemiology than where they trained. Each healthcare system with its unique challenges brings forward a need to develop and enhance a certain skill set. Furthermore, the challenging health needs and advanced knowledge in health and medical science are constantly evolving, resulting in a need to further update medical practice. Many of the skills required to practice medicine are achieved in formal training at the beginning of one's career such as in residency. Aside from these formal training programs, a faculty development program is the primary means of expanding beyond existing skills, which will assist healthcare professionals in multiple roles, ranging from clinical to leadership skills. There are, however, limited opportunities available to formally develop professional skills needed to maintain the practice in the evolving fields of medicine. Healthcare professionals have either acquired skills "on the job" or seek training specific to the needs they feel they need to acquire [1]. Except for clinical updates and leadership roles, faculty develop- 
ment programs may aim to develop several objectives that do not fall in these categories, such as developing inter-professional collaboration and understanding social interaction with patients. Steinert highlighted the importance of faculty development to respond to advances in medical education and healthcare delivery, to continue to adapt to these growing responsibilities and requirements of healthcare professionals in their respective fields in medicine and to expand their focus and consider different training methods and formats and encourage new partnerships and collaborations [2]. Faculty development should also take into consideration as mentioned by Gappa et al, the evolving factors that have important implications on healthcare professionals and their continuing education [3]. These factors include the increasing diversity of learners who come from different cultural and academic backgrounds. Furthermore, effective faculty must support the learning of those learners with diverse learning needs and develop curricula and teaching strategies appropriate to the practice environment.

This evolution of practice is demonstrated in emergency medicine, a speciality that continues to grow in scope, activity and serves as an essential component to patient safety. This consistent evolution covers both scopes of the day-to-day treatment needs as well as the planning and leadership roles for disaster preparedness. There are more than thirty countries that have recognized emergency medicine as a speciality. In those countries where the field is not yet recognized, many are pursuing speciality recognition and developing training programs $[5,6]$. With the increasing complexities of medical training, emergency physicians who take on education leadership roles require an indepth understanding of knowledge transition to be able to identify, train and evaluate the needs of a faculty [4]. Curriculum design for a faculty development program should focus on the desired outcomes that the program aims to achieve to allow healthcare professionals to become more competent. The competency-based education approach allows learners to increase their ability to acquire and integrate knowledge, skills and attitudes in medical practice.

As a country, Kuwait developed a residency program in emergency medicine in 2010 , having graduated the first cohort of board-certified emergency medicine consisting of two doctors in 2015. Presently, there is a deficit in the number of board-certified emergency physicians across the seven ministries of health hospitals. This means that physicians working in the emergency departments in Kuwait have a unique challenge in that they have very minimal training in emergency medicine having mostly trained in internal medicine or general surgery. These physicians who have not trained in Kuwait are not aware of the healthcare system or patient population in the country. Healthcare in Kuwait has emergency departments seeing 1000-1300 cases per day. This high flow of cases accompanied by limited electronic data of the patients' previous history including previous labs, ECGs and medications make treating patients a challenge. Kuwait also has very limited use of the family physicians making the main health contact the emergency department. Therefore, a faculty development program is required to educate these healthcare professionals to become updated in emergency medicine practices as well as team science in day-to-day clinical needs and disaster preparedness. Many patients in Kuwait view emergency physicians as non-specialized junior doctors that only triage patients. Patients believe that the more experienced specialists are the in-house departments such as internal medicine and general surgery, thereby calling on emergency physicians to consult the in-house services. These misconceptions have to be addressed especially with the growing number of specialists in the field that are overseeing the care of patients. Faculty development programs are the cornerstones needed to bridge the gap between board-certified and non-board-certified emergency physicians.

Literature notes that curriculum development for faculty development programs requires strategies for deep interrogation of the needs and gaps. Curriculum development can be achieved using several theories. One of which is Kern's curriculum development which aims to identify the problem through a needs assessment to transform the current approach to an ideal approach and tapering it to fit the learner and the learning environment [7]. In addition, the use of backward design, a method of designing an educational curriculum by setting goals before choosing the instructional methods and forms of assessment is also helpful. It focuses on the required outcomes using the end goal as the driver to construct objectives of the curriculum.

Fink uses the taxonomy of significant learning and focuses on learner development such as that of a faculty [8]. In understanding and addressing the motivational drivers of learners and incorporating them as a part of a curriculum, learners can be more engaged in the learning process. When learners learn something about themselves or others, these human dimensions enable them to interact more effectively to understand the personal and social implications of what they have learned. Using needs assessment to construct the objectives and curricula will give motivational energy to what learners are learning. Lastly, integrating within the curriculum on how to be a better learner will allow learners to be more self-directed and become more effective learners. 


\section{Material and methods}

\section{Literature search}

A systematic review was conducted using the Preferred Reporting Items for Systematic Reviews and Meta-Analysis guidelines (PRISMA). Three databases were systematically searched: PubMed, CINAHL and ERIC from their inception until June 2018 for relevant English-language studies. Institutional Review Board approval was not required for this study as it was a systematic review of the published literature. Literature search strategies in these databases used a combination of subject headings and index terms as well as keywords relating to faculty development, curriculum development and emergency medicine. Multiple searches were performed in each database and an example in PudMed and CINAHL is shown below.

\section{Search \#1}

In the primary search, the search terms used were ("faculty development" or "faculty training") and "needs assessment" and (emergency or trauma). This yielded 12 results in PubMed and 3 results in CINAHL.

\section{Search \#2}

In the secondary search, curriculum development or curriculum design was used as a broader search instead of needs assessment. This was not to miss any other methods of curriculum design. The search terms were ("faculty development" or "faculty training") and ("curriculum development" or "curriculum design") and (emergency or trauma). This yielded 9 results in PubMed and 6 results in CINAHL.

\section{Search \#3}

In the third search, to cover the database ERIC, there were no specific articles related to Emergency Medicine. Two ERIC searches were conducted that used more expanded terms related to medical school faculty in general. The target population to cover graduate medical school was the closest to emergency medicine depicting postgraduate study. The search terms were (DE "Faculty Development") AND (DE "Medical School Faculty" OR DE "Graduate Medical Education" OR DE "Medical Education" OR DE "Medical Schools") AND (DE "Needs Assessment"). This yielded 12 results.

A secondary search was done in ERIC with the substituted term needs assessment for curriculum design and curriculum evaluation as follows, (DE "Faculty Development") AND (DE "Medical School Faculty" OR DE "Graduate Medical Education" OR DE "Medical
Education" OR DE "Medical Schools") AND (DE "Curriculum Development” OR DE "Curriculum Design" OR DE "Curriculum Evaluation”). This yielded 50 results.

\section{Criteria for eligible papers}

Eligible manuscripts had to be full-length peer-reviewed publications that outlined faculty development programs. Broad inclusion criteria included articles that based their research primarily on emergency medicine. Articles were considered if they included a target population of learners that had no formal training in the field, they were currently practising in. Papers were excluded if they were not related to faculty development programs and their curriculum development. The objectives of the faculty development programs were to address both clinical knowledge and non-clinical knowledge such as the flow of patients and leadership skills. Articles outlying the roles or needs of emergency medicine physicians were also reviewed.

\section{Article review process}

The process for reviewing and selecting articles is presented in Figure 1. A total of 92 abstracts were independently reviewed by two authors (SQ and EA). 86 articles remained after removing duplicate articles. Of these, 76 publications were excluded based on abstract review. Abstract inclusion decisions that were discordant between the two reviewers were reconciled between themselves without a third party. 10 papers for full-text review were retrieved, of which 5 were deemed to be eligible for inclusion.

\section{Data analysis}

Two reviewers (SQ and EA) independently extracted data from the 5 papers using a standard data collection protocol that included speciality, faculty development program objectives (whether clinical, educational or administrative), training setting (classroom, clinical setting or simulation), trainee level (junior or senior), curriculum length and methods of instruction. When there were different conclusions between reviewers, further joint discussion led to a final consensus.

\section{Results}

Of the 5 publications between the start of the search engine to June 2018, 2 (40\%) were published in the last 5 years. A summary of key findings is presented in Table 1 with specific characteristics. The objectives of the faculty development program were subdivided into (1) clinical such as cases or bedside teaching, (2) administrative such as leadership roles and (3) business 


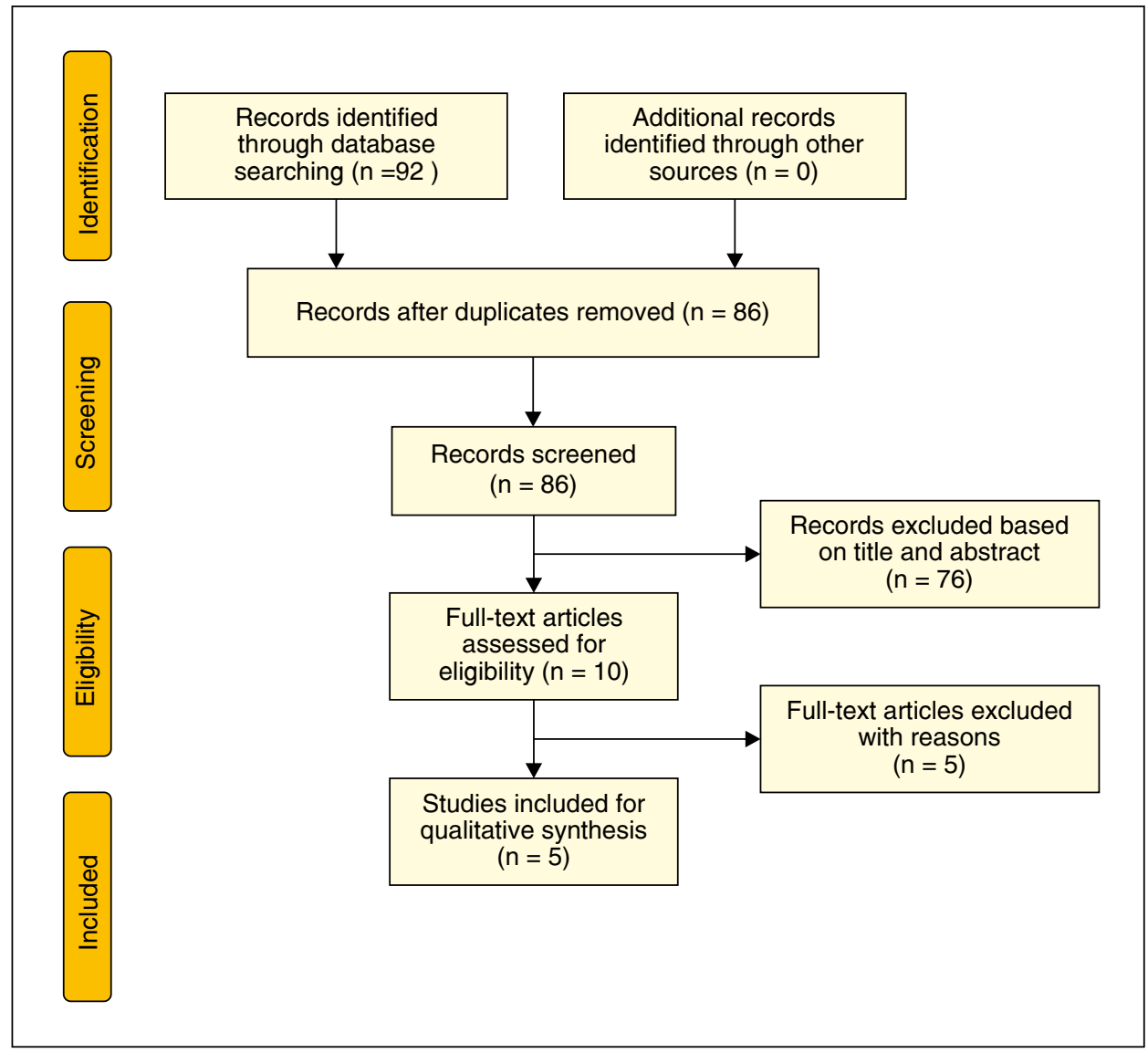

Figure 1. The process of reviewing and selecting articles

Table 1. Summary of key findings extracted from articles used for this study

\begin{tabular}{|c|c|c|c|c|c|c|}
\hline $\begin{array}{l}\text { Author } \\
\text { objectives }\end{array}$ & Speciality & FDP & Setting & Level & Length & Recommended instruction \\
\hline Woods et al. & EM & Educational & Classroom & Senior & Not specified & Mentorship \\
\hline Brown et al. & EM & $\begin{array}{c}\text { Clinical, } \\
\text { educational, } \\
\text { administrative }\end{array}$ & $\begin{array}{l}\text { Classroom, } \\
\text { simulation, } \\
\text { clinical research }\end{array}$ & Junior, Senior & Not specified & Need for FDP \\
\hline Farley et al. & EM & $\begin{array}{c}\text { Clinical, } \\
\text { educational, } \\
\text { administrative }\end{array}$ & $\begin{array}{l}\text { Classroom, } \\
\text { clinical, } \\
\text { simulation }\end{array}$ & Junior & Not specified & Mentorship, bedside, research \\
\hline Bandiera et al. & EM & Educational & Classroom & Senior & Half-day & $\begin{array}{l}\text { Objective setting, feedback, } \\
\text { seeking teaching opportunities }\end{array}$ \\
\hline Alagappon et al. & EM & $\begin{array}{l}\text { Clinical, } \\
\text { educational }\end{array}$ & $\begin{array}{l}\text { Classroom, } \\
\text { clinical research }\end{array}$ & Junior, Senior & Variable & Mentoring, fellowships, rotations \\
\hline
\end{tabular}

EM - emergency medicine

models, educational or research. The level of the learner was subdivided into junior or senior, defined as less than or greater than 10 years in the field respectively. Recommended instruction that originated out of the article included mentorship or coaching techniques that gave a one-on-one level of training while the learner was applying what was learnt.
All 5 articles had education as the main objective of the curriculum for faculty development programs. 3 of the articles had more than one objective, 3 articles had clinical objectives, 2 articles had administrative objectives and 2 articles had a research objective. All 5 of the articles had a faculty development program that was in the classroom setting; they were in lecture format 
as the instructional design of the teaching. Of those five articles, three had a faculty development program that included more than one instructional design as a teaching format. Simulation appeared in all 3 articles and clinical appeared in 2 articles.

Four articles (80\%) included a target audience of senior staff. This included senior emergency physicians either as the sole learners or with junior staff. Four of the articles (80\%) recommended mentoring as an effective method of faculty development. One of the articles recommended faculty development program was needed through a conducted needs assessment without going into detail on the instructional design of the program.

\section{Discussion}

Faculty development programs have continued to be the main form of faculty development after formal training. Emergency medicine being a fast-evolving speciality requires continuity of education to achieve the fast-developing skills. Few opportunities exist during medical training to formally develop these required professional skills [2]. The results of this systematic review suggest that a mentorship or coaching method is recommended as part of faculty development

for learners to learn the required skills. This is particularly true if the skills needed were that of an educational objective.

Apart from formal training certificate and degree programs, faculty development is the primary means of expanding beyond existing skill sets. Faculty development provides "the broad range of activities that institutions use to renew or assist faculty members in their multiple roles. [9]" More recently, the faculty members themselves through focus groups and surveys are constructing the content and format of such programs [10-12]. These needs assessments are useful in identifying the specific gaps in knowledge or training that faculty development can address $[13,14]$.

\section{Limitations}

The current report has several limitations such as not capturing faculty development curricula that have not been published at all, or in the traditional peer-reviewed literature. In addition, although used broad search criteria, the search was focused on emergency departments and limitations of this search were finding studies that conducted their research on a similar target learners' population as the one in Taiba Hospital; healthcare professionals with no training in emergency medicine, although working in an emergency department for many years. The search studies classified the learners as juniors undergoing emergency medicine training or seniors, having completed their residency training. As a result, the faculty development programs focused mostly on non-clinical objectives such as research, educational and administrative needs. Despite searching multiple databases there are likely faculty development programs that have addressed a similar issue but have not published on them.

\section{Conclusions}

Faculty development programs provide the majority of post-residency education and training to keep with the evolving field of Emergency medicine. The most effective method of the faculty development program was through mentorship and pairing healthcare professionals to support each other with clinical and administrative challenges. In follow- up, taking into account the results of the systematic review, a needs assessment was conducted to bring together a curriculum for an inter-professional faculty development program for emergency medicine physicians and nurses at Taiba Hospital in Kuwait. A faculty development program titled Emergency Department Faculty Development Program (ED-FDP) was structured by pairing the board-certified Emergency Department (ED) staff physicians with the non-board-certified staff physicians to provide mentorship for any clinical and/or administrative issues. Further research is needed to dictate faculty development focusing on non-educational objectives.

\section{Appendix}

\section{Demographic}

- What is your job in the hospital?

- How many years have you been working in the ED department since the start of your career?

- Have you attended a faculty development program before? Curriculum structure

- Have you used medical database search engines such as PubMed to give a lecture?

- Which topics would you like a faculty development program to focus on?

- Would you like sessions on-spot diagnosis of cases? E.g., pathognomic rashes, X-ray findings?

Doctors: How confident do you feel while performing the following procedures?

- Point of care ultrasound

- Suturing

- Intubation and airway management

- Casting

- Eye exam 
- Central line insertion

- Managing special populations e.g., pregnant women, paediatrics

- Documentation

- Other: please specify Nurses: How confident do you feel performing the following procedures?

- Triaging

- Assisting in critically ill patients

- Managing special populations e.g., pregnant women, paediatrics

- Other: please specify Instructional design

- Do you feel you would like to focus on the theory of these topics in lecture format?

- Would you like to focus on the clinical component discussing cases

- Do you feel you would like to focus on the partial components?

- Have you attended a design thinking session before?

- Do you agree for the lectures to be recorded?

- Have you ever attended a simulation session before?

- How confident are you in critical appraisal of medical journals?

\section{References}

1. Jouriles NJ, Kuhn GJ, Moorhead JC, et al. Faculty development in emergency medicine. Acad Emerg Med. 1997; 4(11): 1078-1086, doi: 10.1111/j.1553-2712.1997.tb03683.x, indexed in Pubmed: 9383495.
2. Steinert Y. Faculty development in the new millennium: key challenges and future directions. Medical Teacher. 2009; 22(1): 44-50, doi: 10.1080/01421590078814

3. Ward K. Rethinking Faculty Work: Higher Education's Strategic Imperative (review). The Review of Higher Education. 2007; 31(1): 128-129, doi: 10.1353/rhe.2007.0048.

4. McLeod PJ, Steinert Y. The evolution of faculty development in Canada since the 1980s: coming of age or time for a change? Med Teach. 2010; 32(1): e31-e35, doi: 10.3109/01421590903199684, indexed in Pubmed: 20095764

5. Holliman CJ, VanRooyen MJ, Green GB, et al. Planning recommendations for international emergency medicine and out-of-hospital care system development. Acad Emerg Med. 2000; 7(8): 911-917, doi: 10.1111/j.1553-2712.2000.tb02070.x, indexed in Pubmed: 10958132.

6. Alagappan K, Holliman CJ. History of the development of international emergency medicine. Emerg Med Clin North Am. 2005; 23(1): 1-10, doi: 10.1016/j.emc.2004.09.013, indexed in Pubmed: 15663970.

7. Rattner S. Curriculum Development for Medical Education: A Six-Step Approach. Annals of Internal Medicine. 1999; 130(10): 867, doi: 10.7326/0003-4819-130-10-199905180-00028

8. Adapted from the definition used in the 1st and 2nd Inter- national Conferences on Faculty Development in the Health Professions (Toronto, Canada, May 10-13, 2011, and Prague, Czech Republic, August 23-25, 2013). http:// www.facultydevelopment2011.com (21 May 2014).

9. Beasley B. Promotion Criteria for Clinician-Educators in the United States and Canada. JAMA. 1997; 278(9): 723, doi: 10.1001/jama.1997.03550090047031.

10. Coates WC, Hobgood CD, Birnbaum A, et al. SAEM Undergraduate Education Committee. Faculty development: academic opportunities for emergency medicine faculty on education career tracks. Acad Emerg Med. 2003; 10(10): 1113-1117, doi: 10.1111/j.1553-2712.2003. tb00584.x, indexed in Pubmed: 14525747.

11. Steinert $Y$, Mann K, Centeno A, et al. A systematic review of faculty development initiatives designed to improve teaching effectiveness in medical education: BEME Guide No. 8. Med Teach. 2006; 28(6): 497-526, doi: 10.1080/01421590600902976, indexed in Pubmed: 17074699.

12. Baldwin CD, Levine HG, McCormick DP. Meeting the faculty development needs of generalist physicians in academia. Acad Med. 1995; 70(1 Suppl): S97-103, doi: 10.1097/00001888-199501000-00032, indexed in Pubmed: 7826466.

13. QAdkoliBV, Al-UmranKU, Al-SheikhMH, etal.Innovative method of needs assessment for faculty development programs in a Gulf medical school. Educ Health (Abingdon. 2010; 23(3): 389.

14. Holmboe ES, Ward DS, Reznick RK, et al. Faculty development in assessment: the missing link in competency-based medical education. Acad Med. 2011; 86(4): 460-467, doi: 10.1097/ACM.0b013e31820cb2a7, indexed in Pubmed: 21346509 